Doing Many Things at a Time:

Lack of Power Decreases the Ability to Multitask

RUNNING HEAD: Power and Multitasking Performance

Word count: 6133 


\begin{abstract}
Three studies investigated the effects of power on the ability to pursue multiple, concomitant goals, also known as multitasking. It was predicted that powerless participants will show lower multitasking ability than control and powerful participants. Study 1 focused on selfreported ability to multitask in a sample of executives and subordinate employees. Studies 2 and 3 investigated the ability to dual-task and to switch between tasks, respectively, using dual-task and task-switching paradigms. Across the studies, powerless individuals were less able to effectively multitask compared to control and powerful participants, suggesting that the detrimental effects of lack of power extend beyond single task environments, shown in past research, into multitasking environments. Underlying mechanisms are discussed.
\end{abstract}

Keywords: power, multitasking, dual-tasking, task-switching, goal-pursuit 


\section{Doing Many Things at a Time: Powerlessness Decreases the Ability to Multitask}

Lord Chesterfield wrote "there is time enough for everything in the course of the day, if you do but one thing at once, but there is not time enough in the year, if you will do two things at a time" (April 14, 1747). Indeed, a large body of research has supported Lord Chesterfield's intuition that multitasking can be detrimental for performance (Kruglanski, Shah, Fishbach, Friedman, Chun, \& Sleeth-Keppler, 2002; Meyer \& Kieras, 1997; Shah, 2005). Multitasking is cognitively more difficult than single tasking, especially when both tasks require attentional resources. In addition, after multitasking, individuals often show fractured thinking and lack of focus (Ophir, Nass, \& Wagner, 2009).

Nevertheless, the unfavourable consequences of multitasking depend on context and the individuals' ability to multitask (Lehle, Steinhauser, \& Hubner, 2009; Schumacher et al., 2001). One question that arises is whether social factors can impact multitasking ability. Here we examine the effects of power-a ubiquitous social factor present in organizations, intergroup, and interpersonal relations - on multitasking ability. We investigate whether an individual's position in the power hierarchy affects his or her ability to pursue more than one task simultaneously.

Power hierarchies have been prevalent throughout history in both human and animal populations. Power, or an individual's relative ability to possess and control valuable resources and outcomes (Fiske, 1993; Fiske \& Berdahl, 2007; Fiske \& Dépret, 1996; Keltner, Gruenfled, \& Anderson, 2003), affects the ways individuals feel, think and act (for reviews see Guinote, in press; Keltner et al., 2003). In particular, power facilitates, and powerlessness hinders, selfregulation and the attainment of goals (DeWall, Baumeister, Mead, \& Vohs, 2011; Guinote, 2007a; Overbeck \& Park, 2006; Scheepers, de Wit, Ellemers, \& Sassenberg, 2012; Schmid, 
Kleiman, \& Amodio, 2015). These differences derive from the ways power affects people's strategies during the pursuit of their aims and desires (Guinote, 2007c; Schmid, Schmid Mast, \& Mast, 2015). Differences in central executive ability (Guinote, 2007b; Harada, Bridge, \& Chiao, 2012; Smith, Jostmann, Galinsky, \& van Dijk, 2008; Schmid et al., 2015; see Guinote, in press) may also contribute to performance effects. Central executive functions are high-level cognitive processes necessary for controlling, organizing, and monitoring information and influence performance across a range of different areas (Baddeley, 1996; Baddeley \& Della Sala, 1996; Miyake, Friedman, Emerson, Witzki, Howerter, \& Wager, 2000).

This evidence has focused on behaviour and cognitive functions associated with the pursuit of single goals. In this article, we examine, for the first time, whether power affects performance during the pursuit of multiple goals (i.e., during multitasking). Individuals often need to complete tasks related to different goals simultaneously (e.g., dual-tasking) or in rapid succession by switching between them (i.e., task-switching). With modern technology and workplace flexibility, people constantly need to do more than one task at a time. Whether driving and talking, or responding to email notifications while working on tasks, acting on multiple inputs is common (Lindbeck \& Snower, 2000).

In fact, $34 \%$ of media usage time is spent on multiple media simultaneously (Brasel \& Gips, 2011), and computer users tend to change windows or check other programs nearly four times per minute during laboratory experiments (Brasel \& Gips, 2011) and 37 times an hour during real-life work situations (Foehr, 2006). Moreover, employees typically spend more than a quarter of their daily work time checking, answering, and organizing emails (Bates, 2012). A study focusing on information workers found that the average time employees spend on one continuous, uninterrupted segment of work before switching to another task 
was only 10.5 minutes (González \& Mark, 2005). Given the prevalence of multitasking, organizations often seek and assess multitasking ability as part of their routine employment selection procedures (Appelbaum, Marchionni, \& Fernandez 2008; González \& Mark, 2005; Lindbeck \& Snower, 2000). Yet it remains unknown whether people's level of power will affect the expression of these abilities.

An extensive line of research found that high demands and limited control over the ways people complete their tasks at work — a form of powerlessness—decreases productivity, as well as wellbeing and health (Elovainio et al., 2016, Marmot, 2000, Seibert, Wang, \& Courtright, 2011). It is possible that lack of power decreases multitasking ability, and this contributes to the differences in productivity found in these studies. Investigating whether people's position in the power hierarchy affects multitasking ability is important for individuals and organizations. In organizations power holders assign tasks and deadlines to subordinates, and therefore have the power to stimulate or decrease multitasking at work.

\section{Power and Single Goal Pursuit}

Research has demonstrated that power facilitates the attainment of ones' aims and desires (e.g., Guinote, 2007d; Magee, Galinsky, \& Gruenfeld., 2007). Powerholders benefit from increased freedom, security, and rewards, and have more control over their own as well as the other's outcomes (Magee \& Galinsky, 2008; Sidanius \& Pratto, 2001). As a consequence, powerholders are able to devote their undivided attention to their primary goals and needs, and regulate their behaviours accordingly (Galinsky, Gruenfeld, \& Magee, 2003; Guinote, in press, 2007a). In contrast, powerlessness increases dependency, restraints, and potential threats (Fiske \& Berdahl, 2007). Powerless people are deprived from a core need to have control. Therefore, they need to pay attention to various sources of information, including 
their superiors and the task at hand, to predict the future and potentially increase control (Anderson \& Berdahl, 2002; Fiske, 1993; Keltner, et al., 2003). Consequently, lack of power can be detrimental to all phases of single goal-pursuit, such setting goals, initiating goal pursuit, missing opportunities for goal consistent behavior, and persisting until the goal is attained (Guinote, 2007c; see also Guinote, in press). These findings raise the possibility that lack of power will also be detrimental to multiple goal pursuit. This is ironic given that powerless individuals prefer to multitask when pursuing multiple goals (Cai \& Guinote, 2016; Schmid, et al., 2015). This preference further highlights the importance of understanding how powerlessness affects performance during multitasking.

The underperformance of powerless individuals in single tasks is in part related to decreased cognitive abilities. With divided attention and increased concerns, powerless individual underperform on central executive tasks involved in planning and implementing single goals (DeWall et al., 2011; Guinote, 2007c; Harada et al., 2012; Slabu \& Guinote, 2010; Smith et al., 2008). For example, participants assigned to a powerless role had impaired ability to update task relevant information and to inhibit irrelevant information (DeWall et al., 2011; Guinote, 2007b; Smith et al., 2008).

In addition, powerless individuals are more cautions and inhibited, and these motivational inclinations also hinder effective single goal pursuit. For example, during negotiations powerless individuals often do not initiate offers, and this leads to worse deals (Magee, Galinsky, \& Gruenfeld, 2007). Motivational factors could also contribute to powerless individuals' underperformance in multitasking contexts. 


\section{Power and Multitasking Ability}

Successful multitasking typically engages a special type of central executive functions associated with dual-tasking and task-switching. During multitasking, people need to select tasks, quickly re-focus attention, switch, coordinate inputs, and minimize cross-talk and interference between various relevant cues (Kushleyeva et al., 2005). These executive functions are required only when multiple tasks are performed concurrently, and not when they are performed separately as single tasks.

Executive functions are not unitary (Friedman, Miyake, Corley, Young, DeFries, \& Hewitt, 2006; Miyake et al., 2000). Central executive tasks previously examined, such as inhibition (see Smith et al., 2008), are less relevant during dual-tasking since it is necessary to keep both tasks activated to a certain degree (Miyake et al., 2000). Importantly, central executive tasks related to multitasking have not yet been examined in the power literature.

Multitasking is typically more difficult than single-tasking, as additional executive functions are needed to minimise interference between two or more tasks and to schedule the order for task processing (Fishbach \& Ferguson, 2007, Kruglanski et al., 2002; Shah, 2005). Multitasking is therefore highly dependent on working memory capacity (WM, a system that temporarily holds information for reasoning and further information processing; Baddeley, 1996).

WM assists in the mental operations required to inhibit a currently activated task, switching to the interrupted task, and reinstating the initial task once processing for the interrupted task has finished (Buhner, Konig, Pick, \& Krumm, 2006; Hambrick, Oswald, Darowski, Rench, \& Brou, 2009; Rubinstein, Meyer, \& Evans, 2001; Schubert, 2008). Reduced WM capacity, which often occurs under powerless conditions (Guinote, 2007; Smith et al., 2008) could impair 
multitasking performance. Thus the hypothesis presented here that powerlessness decreases multitasking ability is consistent with the notion that multitasking and single tasking involve mental operations that are dependent on a common factor, WM capacity, which allows individuals to hold information accessible during central executive procedures.

We focus primarily on powerless individuals. This is because evidence regarding the effects of having power on WM capacity has been mixed (DeWall et al., 2011; Harada et al., 2012; Schmid et al., 2015, Smith et al., 2008). Thus we hypothesized that having power will not affect multitasking ability.

\section{Overview of the Current Research}

The aim of the present research was to investigate whether being in a high or low power position affects multitasking ability. This was examined by first asking employees with different power positions to report their ability to multitask in work settings (Study 1). Two further experiments were conducted to examine the speed and accuracy of responses during dual-tasking (Study 2) and task-switching (Study 3). Here power was manipulated by asking participants to recall an event in which they possessed power (powerful condition), lacked power (powerless condition) or were in a neutral situation (control condition; following Galinsky et al., 2003). Throughout the studies, we ruled out the influences of mood (Studies 2 and 3) and anxiety (Study 3), as these factors may affect multitasking ability (Carver, 2003; Rokke, Amell, Koch, \& Andres, 2002) and have been related to power (Briñol, Petty, Valle, Rucker, \& Becerra, 2007; Fast, Sivanathan, Mayer, \& Galinsky, 2012; Keltner et al., 2003). Drawing on previous work showing that powerlessness can be detrimental for the pursuit of single goals, for WM and central executive functions, we predicted that it will also decrease multitasking ability. 


\section{Study 1: Attentional-Control and Self-Regulation During Multitasking}

Study 1 was designed to obtain preliminary evidence for power differences in multitasking performance in an ecologically valid context. Multitasking ability was measured using the Attentional-Control-Scale (ACS; Derryberry\& Reed, 2002) and two subscales (goal planning and implementing) of the Self-Regulation-Questionnaire (SRQ; Brown, Miller, \& Lawendowski, 1999). The ACS measures an individual's ability to focus and shift attention between various tasks. The SRQ measures the ability to plan, implement, and maintain behaviour when faced with multiple demands. Participants held actual powerful (manager) and powerless (subordinate employee) roles in organizations. It was predicted that a subordinate, compared to a managerial, position would decrease the ability to deploy attentional strategies necessary to multitask and would decrease multitasking ability.

\section{Methods}

Participants and design. Forty-nine full-time employees (23 managers and 26 subordinates) participated in this study. Managers (5 females and 18 males) worked in a variety of businesses (e.g., banking, technology, education). All managers had subordinates under their supervision. Eleven managers (48\%) occupied middle management, and 12 (52\%) occupied top management positions. Thirteen percent had five or fewer subordinates, $39 \%$ had 5 to 25 subordinates, and $48 \%$ were in charge of more than 25 subordinates. The managers were aged between 26 and 54 years $(M=42.7, S D=8.14)$. All subordinate employees (13 females and 13 males) worked under the supervision of one or more managers. Most subordinates (75\%) were office workers in clerical positions (e.g., advisors, administrators, assistants). The subordinates were between 19 and 56 years old $(M=32.2, S D=9.03)$, and none of them had personnel 
responsibilities. The study was a between subjects design with two power conditions (managers vs. subordinates). Participation was voluntary.

Materials and procedure. The ACS (Derryberry \& Reed, 2002) contains 20 items measuring the ability to focus attention when faced with distracting opportunities to multitask (e.g., It's very easy for me to concentrate on a difficult task when there are noises around), the ability to shift attention between different tasks (e.g., I can quickly shift from one task to another), and the ability to balance attention during dual-tasking (e.g., It is easy for me to read or write while I'm also talking on the phone).

The two subscales of the SRQ (Brown et al., 1999) consist of 17 items measuring the ability to make plans and decisions when faced with multiple demands (e.g., I can easily make up my mind about things) and the ability to implement plans (e.g., I have so many plans that it's hard for me to focus on any one of them, reverse scored). Responses were given on scales ranging from 1 (almost never) to 4 (almost always). Upon completion, participants were debriefed and thanked for their participation.

\section{Results and Discussion}

Gender did not affect the responses, $F<1$, therefore this factor was not considered in further analyses. To ensure that differences in age across managers and subordinates did not account for the effects of power, this factor was controlled for. Two ANCOVAs were conducted on the ACS and SRQ scores, with power (subordinate vs. manager) as a between subjects factor, and age as a covariate. This analysis yielded a significant effect of power for the ACS score, $F(1,46)=4.60, p=.037, \eta_{\mathrm{p}}{ }^{2}=.091,95 \%$ CI $[3.28,3.57]$, and the SRQ score, $F(1$, $46)=20.32, p<.001, \eta_{\mathrm{p}}^{2}=.31,95 \% \mathrm{CI}[3.63,3.88]$. As predicted, the ability to control attention during multitasking and to deal with the difficulties of planning and implementing plans when 
faced with multiple goals was lower in subordinates $(M=3.30, S D=0.41)$ compared to managers $(M=3.88, S D=0.40)$. No other effects were significant.

In summary, being in a subordinate (vs. managerial) position was associated with lower self-reported ability to self-regulate during the pursuit of multiple goals. Compared to subordinate employees, managers reported that they could more easily balance attention between multiple goals and implement multiple plans and tasks.

\section{Study 2: Dual-Tasking Ability}

The aim of Study 2 was to examine actual multitasking performance. This study utilized a dual-task paradigm that requires participants to perform two tasks with a temporal overlap. Dual-task paradigms mimic one of the strategies often used by multitaskers: that of trying to complete the two tasks simultaneously (Bluedorn et al., 1999). Responses during dual-tasking are often delayed and less accurate compared to responses to each task when performed in isolation. This occurs because dual-tasking requires additional WM resources to monitor and coordinate attentional processes linked to the two tasks (Lavie, Hirst, De Fockert, \& Viding, 2004; Szameitat, Schubert, Muller, \& von Cramon, 2002). Insufficient WM capacity may enhance cross-talk and confusions between the tasks, decreasing independent representations for the two tasks.

In the present study, participants performed an auditory and a visual task either independently (single-tasking) or simultaneously (dual-tasking; adapted from Levy \& Pashler, 2001). We expected powerless participants to have higher differences in performance between single and dual-tasking (i.e., higher dual-task costs) compared to control and powerful participants. 


\section{Methods}

Participants and design. Sixty participants from a European university (32 females; mean age $=24.9)$ took part in exchange for course credits. Four participants were excluded from the analyses: one for not following instructions regarding the essay topic and three for being outliers (see results section). Thus, 56 participants (30 females, mean age $=24.8$ ) were included in the final analyses. The study was a 3(power: powerful, control, powerless) x 2(tasks: single, dual) x 2(modality: auditory, visual) mixed design, with power as a between-subjects factor. Participants were randomly assigned to the power conditions.

Materials and procedure. Participants were informed that they would take part in two unrelated studies. The first study was ostensibly described as investigating how people recall past events. Following Galinsky et al. (2003), participants wrote a narrative essay about an incident in which they had power (powerful) or did not have power (powerless), or the last time they went to the supermarket (control). Power was defined as having control over the ability of someone to get something they wanted, or being in a position to evaluate others.

Participants then completed an auditory and visual categorization task on a computer. All trials began with a warning stimulus consisting of three adjacent horizontal white lines (2.2 $\mathrm{cm}$ in length), displayed in the centre of the screen against a black background for $501 \mathrm{~ms}$ (see Figure 1). The distance between the lines was $1.2 \mathrm{~cm}$. For single-auditory trials, a computer generated tone was emitted for $40 \mathrm{~ms}$. Tone frequency was selected at random from one of three values $(220,880,3520, \mathrm{~Hz})$, and participants responded by saying one, two or three, respectively. Vocal responses were tape-recorded to determine error-rates (ERs). A voice key registered reaction-times (RTs). A new trial began 1,500 ms after participants' response. For the single-visual trials, a solid, white, circular disk (radius, $2.2 \mathrm{~cm}$ ) replaced one randomly 
selected line that appeared during the warning stimulus. The display remained visible until participants responded to the circle's location by pressing the third, fourth or fifth key on the E-prime Serial Response Box using their index, middle, or ring fingers of their dominant hand. The three possible locations of the circle and the three response keys were spatially compatible. For the dual-task, both visual and auditory stimuli were presented simultaneously. Participants were instructed to respond to both.

Participants started off with a practice of 8 trials of each of the three block types (auditory-single, visual-single, and dual). This was followed by the test session of 6 blocks (48 trials per block) with each block type appearing twice. Participants were informed what block type to expect, and block order was counterbalanced across participants.

To verify that participants in the powerful condition perceived themselves as being more in charge relative to those in the powerless condition, participants were asked to indicate on a 9-point scale the extent to which they felt in charge of the situation that they recalled. In addition, to assess any possible mood effects on WM capacity and multitasking performance (Seibert \& Ellis, 1991), participant's mood was assessed using a 4-item mood questionnaire ranging from -3(very sad, very discontent, very tense, very bad) to 3(very happy, very content, very calm, very good). Participants were then probed for suspicion, thanked, and debriefed.

\section{Results and Discussion}

Manipulation check. An independent-samples $t$-test revealed that powerful participants felt more control $(M=7.37, S D=1.01)$ than powerless participants $(M=3.23, S D=2.20)$, $t(31)=7.16, p<.001, \eta_{\mathrm{p}}^{2}=.62,95 \%$ CI $[-5.83,-3.00]$. Thus the manipulation of power was successful. 
Reaction-times. Following Levy and Pashler (2001), trials on which responses were incorrect (3.3\% of all responses), faster than $150 \mathrm{~ms}$ or slower than $3,000 \mathrm{~ms}(4.7 \%$ of all responses), were excluded. Trimmed RTs were then analysed using a 3(power: powerful, control, powerless) x 2 (task: single, dual) x 2(modality: auditory, visual) mixed ANOVA with power as a between-subjects factor. As expected, dual-tasking was more demanding than single-tasking, as indicated by a main effect of task, $F(1,53)=134, p<.001, \eta_{\mathrm{p}}{ }^{2}=.72,95 \% \mathrm{CI}$ [163, 237] with slower dual-task RTs $(M=726, S D=213)$ than single-task RTs $(M=516$, $S D=81)$.

Importantly, the expected task x power interaction was significant, $F(2,53)=4.12, p=.022$, $\eta_{\mathrm{p}}{ }^{2}=$.14. Further analyses using Fisher's Least Significant Difference showed that the difference between single and dual-task performance (i.e., dual-task cost) was higher for powerless $(M=272, S D=177)$ than control $(M=157, S D=121), p=.01,95 \%$ CI $[28.6,200]$ and powerful $(M=174, S D=75.4)$ participants, $p=.027,95 \%$ CI $[11.4,183]$ (see Table 1$)$. There was no difference between control and powerful participants, $p=.69$. Thus powerless individuals had less WM capacity needed for dual-task coordination (see Baddeley, 1996; 2000) than control and powerful participants.

There was also a main effect of modality $F(1,53)=401, p<.001, \eta_{\mathrm{p}}^{2}=.88,95 \%$ CI $[-322,-$ $261]$ such that auditory RTs $(M=768, S D=151)$ were slower than visual RTs $(M=475, S D=142)$. In addition, there was a modality $\mathrm{x}$ power interaction, $F(2,53)=3.62, p=.034, \eta_{\mathrm{p}}{ }^{2}=.12$. The differences between auditory and visual RTs were smaller for powerless participants $(M=235$, $S D=89.1)$ compared to control $(M=320, S D=115), p=.021,95 \%$ CI $[-157,-13.4]$ and powerful participants $(M=317, S D=118), p=.021,95 \%$ CI $[-154,-10.4]$. There was no difference between powerful and control participants, $p=.93$. Hence powerful and control participants were faster 
at the visual than the auditory task, whereas powerless participants' RTs were more similar between the two tasks. No other effects were significant.

Error-rates (ERs). ERs were subjected to a 3(power: powerful, control, powerless) $\mathrm{x}$ 2(task: single, dual) x 2(modality: auditory, visual) mixed ANOVA with power as a betweensubjects factor. There was a main effect of task, $F(1,53)=16.3, p<.001, \eta_{\mathrm{p}}{ }^{2}=.24,95 \%$ CI $[0.54$, 1.73], with higher dual-task ERs $(M=3.87, S D=0.29)$ than single-task ERs $(M=2.66, S D=0.26)$. Thus, dual-tasking was attentionally more demanding than single-tasking. The main effect of power was also significant, $F(2,53)=3.99, p=.024, \eta_{\mathrm{p}}{ }^{2}=.13$. As shown in Table 1 , powerless participants had higher ERs $(M=4.14, S D=0.41)$ than powerful participants $(M=2.54$, $S D=0.40), p=.007,95 \%$ CI $[0.26,2.43]$, and marginally higher than control participants $(M=3.13, S D=0.40), p=.083,95 \%$ CI [-2.01, 0.22]. Participants in the control group did not differ from participants in the powerful condition, $p=.30$. The interaction between power and task did not reach significance, $F<1$. This result indicates that powerless participants had higher ERs across the single- and dual-tasks compared to participants in the other two conditions. Importantly, these results indicate that there was no trade-off between speed and accuracy, and that the increased dual-task cost in reaction-time of powerless individuals was not a by-product of providing more accurate answers.

The analysis also revealed a main effect of modality $F(1,53)=93.2, p<.001, \eta_{\mathrm{p}}{ }^{2}=.64,95 \%$ CI $[0.54,1.73]$, with higher auditory $(M=5.49, S D=0.45)$ than visual ERs $(M=1.04, S D=0.13)$. In addition, there was a modality $\mathrm{x}$ task interaction, $F(1,53)=9.15, p=.004, \eta_{\mathrm{p}}{ }^{2}=.15,95 \%$ CI [$2.57,-0.16]$, with higher dual-task costs for the auditory modality $(M=2.05, S D=4.08)$ than the visual modality $(M=0.35, S D=1.31)$. No other effects were significant. Power did not affect $\operatorname{mood}, F(2,53)=.93, p=.40$. 
Together the results support the hypothesis that powerlessness decreases WM capacity and multitasking ability.

\section{Study 3: Task-Switching Ability}

One strategy that people often use during multitasking is constantly switching between goals (Oswald, Hambrick, \& Jones, 2007). Study 3 examined whether power affects this ability. Switching between different task-sets incurs higher costs (i.e., switching costs) compared to when people continue working on the same task (Rogers \& Monsell, 1995; see Monsell, 2003, for a review). This is due to higher demands on WM resources, as more resources are needed to refocus attention between different tasks. These include retrieving taskrelated intentions and rules, reconfiguring task-sets, inhibiting interfering activations from the previous task-set, and selecting appropriate responses (Mayr \& Keele, 2000). If powerless individuals have less WM capacity, as demonstrated in Study 2, and difficulty in hierarchical task selection, then they should also be less able to respond to the challenges associated with task-switching.

In Study 3, participants were simultaneously presented with two stimuli (letter and number) and switched between the classification of one or the other stimulus, following Ophir et al. (2009). We expected powerless participants to have greater switching costs compared to control and powerful individuals. Powerlessness has been proposed to activate the behavioural inhibition system associated with negative mood and anxiety (Gray, 1982; Keltner et al., 2003), and anxiety increases switching costs (Derakshan \& Eysenck, 2009). Therefore, the role of state anxiety was examined in this study, as well as the role of mood. 


\section{Methods}

Participants and design. Sixty participants from a European university (44 females; mean age $=23.3$ ) took part in exchange for payment. The study was a 3(power: powerful, control, powerless) x 2(switch: switch, repeat) x 2(congruency: congruent, incongruent) mixed design, with power as a between-subjects factor. Participants were randomly assigned to the power conditions, and were paid for participation.

Materials and procedure. Power was manipulated as it was in Study 2. Subsequently, participants completed the task-switching paradigm on a computer (see Figure 2). In this task, participants switched between classifying numbers and classifying letters, according to a cue presented before each trial. The cue, either "NUMBER" or "LETTER", was presented for 200 ms and was followed by a stimulus consisting of a digit and a letter (e.g., "2 b" or "b 2"). Participants were asked to classify the stimuli by pressing one of two buttons with their left and right index fingers. If shown the NUMBER cue, participants were asked to press the left button for an odd number and the right button for an even number. If the LETTER cue was shown, participants were instructed to press the left button if the letter in the stimulus was a vowel and the right button if it was a consonant. The response mapping was counterbalanced across participants. Half of the trials were congruent, such that participants could respond to either cue by pressing the same button regardless of the cue (e.g., 1 a). Half of the responses were incongruent, where participants had to respond using different buttons depending on whether the cue was NUMBER or LETTER (e.g., 1 p). Incongruent responses are more difficult than congruent responses, and should therefore yield higher switching costs (Kiesel, Wendt, \& Peters, 2007). 
The vowels used consisted of the letters a, e, i, and $\mathrm{u}$, and the consonants consisted of $\mathrm{p}, \mathrm{k}, \mathrm{n}$, and $\mathrm{s}$. The set of even numbers consisted of $2,4,6,8$, and the set of odd numbers consisted of $3,5,7$, and 9 . The positions of the number and letter were counterbalanced across the trials. The interval between cue offset and stimulus onset was $226 \mathrm{~ms}$ and the inter-trial interval was $950 \mathrm{~ms}$. Participants first performed 20 practice trials followed by 80 experimental trials, with an equal frequency of same-trial sequences, yielding $40 \%$ switch-trials and $60 \%$ repeat-trials. A repeat trial is one that is preceded by the same cue (e.g., a "NUMBER" trial followed by another "NUMBER" trial), whereas a switch trial is preceded by a trial with a different cue (e.g., a "NUMBER" trial followed by a "LETTER" trial). The differences in RTs and ERs between repeat and switch trials represent switching costs.

Participants then completed the manipulation check and mood scales used in Studies 2 and 3, as well as the State-Trait-Anxiety-Inventory (Marteau \& Bekker, 1992). Finally, they were debriefed and thanked for their participation.

\section{Results and Discussion}

Manipulation check. An independent-samples $t$-test revealed that powerful participants felt more control $(M=5.44, S D=2.41)$ than powerless participants $(M=3.39, S D=1.82)$, $t(34)=2.89, p=.007, \eta_{\mathrm{p}}{ }^{2}=.20,, 95 \% \mathrm{CI}[-3.50,-0.61]$. The manipulation of power was therefore effective.

Reaction-times. Following Ophir et al., 2009, trials that were incorrect $(1.2 \%$ of all responses) and trials that were faster than $200 \mathrm{~ms}$ or slower than $3,500 \mathrm{~ms}(2.6 \%$ of all responses) were excluded. Participants whose ERs were higher than 3 SDs above the mean were also excluded $(N=3)$. Trimmed RTs were then analysed using a 3 (power: powerful, control, powerless) x 2 (trial: repeat, switch) x 2 (congruency: congruent, incongruent) mixed 
ANOVA with power as a between-subjects factor. This analysis yielded an expected main effect of trial, $F(1,54)=85.8, p<.001, \eta_{\mathrm{p}}{ }^{2}=.61$. As shown in Table 2, RTs during repeat trials were faster $(M=1138.42, S D=310.47)$ than during switch trials $(M=1349.24, S D=374.63), 95 \%$ CI [-255, -165]. This result indicates that participants experienced task-switch interference. No other effects were significant.

Error-rates. ERs were then subjected to a 3 (power: powerful, control, powerless) x 2 (trial: repeat, switch) x 2 (congruency: congruent, incongruent) mixed ANOVA with power as a between-subjects factor. This analysis yielded a main effect of trial, $F(1,54)=8.71, p=.005$, $\eta_{\mathrm{p}}{ }^{2}=.14,, 95 \%$ CI [-0.008, -0.001$]$, with higher ERs for switch $(M=1.44, S D=1.54)$ compared to repeat $(M=0.99, S D=1.13)$ trials. Switching across tasks was therefore more costly than repeating the same task.

More importantly, there was a significant power $\mathrm{x}$ trial interaction, $F(1,54)=6.96, p=.002$, $\eta_{\mathrm{p}}{ }^{2}=.21$. Further analyses using Fisher's Least Significant Difference showed that the difference between switch and repeat trials (i.e., switching cost) was higher for powerless $(M=1.25, S D=1.28)$ than control $(M=-0.18, S D=0.48), p=.001,95 \%$ CI $[0.51,1.76]$ and powerful $(M=0.3, S D=0.87), p=.014,95 \%$ CI $[0.16,1.36]$ (see Table 2). There was no difference between control and powerful participants, $p=.22$. This result shows that powerlessness decreased performance when participants switched across tasks.

The ANOVA also yielded a significant main effect of congruency, $F(1,54)=22.2, p<.001$, $\eta_{\mathrm{p}}{ }^{2}=.29,, 95 \%$ CI $[-0.89,-0.35]$. ERs were lower for congruent $(M=0.83, S D=1.08)$ compared to incongruent $(M=1.28, S D=1.27)$ trials. There was also a significant congruency $\mathrm{x}$ trial interaction, $F(1,54)=9.60, p=.003, \eta_{\mathrm{p}}{ }^{2}=.15$. For congruent trials, ERs did not differ between switch $(M=0.85, S D=1.14)$ and repeat $(M=0.79, S D=1.03)$ trials, $t(56)=0.38, p=.70$. However, 
for incongruent trials, ERs were significantly higher for switch $(M=2.01, S D=1.93)$ compared to repeat $(M=0.95, S D=0.99)$ trials, $t(56)=3.32, p=.002,95 \%$ CI $[-1.07,-0.26]$. No other effects were significant. Power did not affect mood and state anxiety, $p>.1$. Overall, the results supported the hypotheses. Powerlessness increased ERs associated with switching across different tasks. The fact that having or lacking power did not affect RTs but only ERs indicates that there was no speed vs. accuracy trade-off in performance. These findings are consistent with the results of Studies 1 and 2. None of these effects were triggered by mood and state anxiety.

\section{Meta-analysis}

A meta-analysis was conducted to establish the robustness of the findings across the three combined studies. All analysis and computations were carried out using Comprehensive Meta-Analysis (Borenstein, Hedges, Higgins, \& Rothstein, 2005), following the procedures outlined by Lipsey and Wilson (2001). A random effects model was used to calculate the mean effect size. Random effects models are more conservative than fixed effects parameters, and are recommended when analysing a small number of studies that have small sample sizes, and when data sets have heterogeneous effect sizes (Lipsey \& Wilson, 2001).

The meta-analysis showed that the weighted average effect size across all three studies was large $(d=1.01, p<.01,95 \% \mathrm{CI}=.059,1.43, n=3$ studies $)$. This means that the effect of power on multitasking performance was large, according to Cohen's criteria (Cohen, 1988), and that overall powerless participants had poorer multitasking performance than powerful participants. Effect sizes were homogeneous $(Q=2.68, p=.26)$. 


\section{General Discussion}

Three studies investigated the effects of power on multitasking ability. Lack of power has a number of detrimental consequences for individuals. Powerless individuals take longer to make decisions and act, are vigilant and pay attention to multiple sources of information (Galinsky et al., 2003; Guinote, in press, 2007a). This absorbs attentional resources (Derakshan \& Eysenck, 2009; Hester \& Garavan, 2005) and decreases the ability to control attention during single goals (Guinote, 2007c: Smit et al., 2008). Therefore, we hypothesized that lack of power would impair multitasking performance. Across all three studies, lack of power negatively affected self-reported, as well as actual multitasking ability during dual-tasking and taskswitching. Given that sample sizes were relatively small a meta-analysis was also conducted. The meta-analysis yielded a large effect size, confirming the results of the individual studies.

The results were not driven by mood (Studies 2 and 3) or anxiety (Study 3). The selfreported multitasking difficulties experienced by employees compared to managers in Study 1 are consistent with the notion that lack of power can impair the ability to multitask across a variety of real life contexts and not only in experimental paradigms. In addition, the effects reported in this article were observed for participants in actual power positions in organizations (Study 1) and in experimental power conditions (Studies 1 and 2). Together these studies provide consistent evidence that low power decreases multitasking performance regardless of how power is operationalized or the multitasking context. It is important to point out that performance for high-power conditions did not differ significantly from control conditions for Studies 2 and 3. Unfortunately, our power manipulation checks did not provide a baseline measure, thus this result could be due to an unsuccessful high-power manipulation. Although past studies using similar designs have successfully manipulated high-power (Lammers, 
Dubois, Rucker, \& Galinsky, 2013), future research should include manipulation checks for all three conditions.

The current findings is in line with previous research, where lack of power was found to decrease central executive ability during single tasking (DeWall et al., 2011; Guinote, 2007b; Smith et al., 2008) and single goal pursuit (Galinsy et al., 2003; Guinote, 2007c). These include delayed action, decreased cognitive flexibility and persistence, and difficulties maintaining goal-directed behaviour and attention (Guinote, 2007c, 2008; DeWall et al., 2011; Harada et al., 2012; Slabu \& Guinote, 2010). While the present results are consistent with previous findings, they represent a novel understanding of how lack of power affects individuals in more complex contexts, characterized by multiple inputs and activities that individuals need to carry out on a daily basis.

If powerless individuals are vigilant and prefer to multitask (Cai \& Guinote, 2016; Schmid et al., 2015), this inclination does not contribute to better performance. Past research had demonstrated that practice of multitasking can decrease task-switching cost and improve performance on switch-task, but not on dual-tasks, which are performed simultaneously (Alzahabi \& Becker, 2013).

The present results also help in understanding the effects of power on cognitive processes, especially since executive functions are not unitary (see Miyake \& Friedman, 2012; Mayiake, Friedman, Emerson, Witzki, Howerter, \& Wager, 2000). Multitasking requires unique executive functions not examined previously in the context of power and lack of power (Smith et al., 2008). As mentioned above, dual-tasking does not involve typical executive functions, such as inhibition and updating (see Miyake et al., 2000), which were previously 
examined. Instead, additional functions are required such as attentional refocusing, switching, and coordinating.

How can one then explain the parallel underperformance found for single executive functions, dual-tasking, and task-switching among powerless individuals? While this question awaits further research, it is plausible that the similarities derive from a domain general component of WM (see Baddeley, 1996; Mitchell, Macrae, \& Gilchrist, 2002), which is a flexible but limited resource system (see Kane, Hambrick, Tuholski, Wilhelm, Payne, \& Engle, 2004). WM allows the maintenance of information necessary for executive operations. Variation in WM capacity, associated with individual differences or temporary WM load, decrease performance on various central executive tasks (see Mitchell et al., 2002). Reduced WM capacity seems the reason why powerless individuals have poor executive functions (see Smith et al., 2008).

The current research provides important applied implications, particularly for organizations. Multitasking ability is an increasingly sought after skill in prospective employees (Appelbaum et al., 2008; González \& Mark, 2005; Lindbeck \& Snower, 2000). Many occupations involve new technologies with multiple operations and notifications that prompt employees to multitask. In addition, subordinate employees have less control over their work compared to individuals who are not powerless. Whereas the latter may decide to prioritize some tasks over others, the former may not be able to do so.

At the same time the present findings corroborate an extensive line of work showing the benefits of empowerment for employees and organizations (Bill, 2010; Hassan, Wright, \& Park, 2016; Fernandez \& Moldogaziev, 2011; Wallace, Johnson, Mathe, \& Paul, 2011). Employee's feelings of powerlessness, for example, through high demands and low control, 
can impair multitasking ability and decrease productivity (Elovainio et al., 2016). Importantly, our results suggest that enhancing employee's sense of power and control could enhance work performance.

One possible limitation is that actual performance was measured only during cued (or forced) multitasking paradigms, so how power affects voluntary multitasking remains unclear. The dual-tasking and task-switching paradigms of Studies 2 and 3 were chosen because they have been designed to explicitly examine performance (Levy \& Pashler, 2001; Rubinstein et al., 2001) and control for differences in familiarity and learning associated with idiosyncratic choices that occur when people freely navigate across tasks. During voluntary multiple goal pursuit, individuals multitask at their own discretion and have greater anticipatory control compared to when multitasking is enforced (Arrington \& Logan, 2004, 2005).

\section{Conclusion}

The current research showed that lacking power — a ubiquitous social factor (Fiske, 1993; Keltner et al., 2003) — has a fundamental impact on how capable people are at multitasking. The present research showed that lack of power is detrimental to both forms of multitasking - pursuing multiple goals simultaneously and with switching rapidly between different goals. 


\section{References}

Alzahabi, R., \& Becker, M. W. (2013). The association between media multitasking, taskswitching, and dual-task performance. Journal of Experimental Psychology Human Perception \& Performance, 39(5), 1485-95. doi:10.1037/a0031208.

Anderson, C., \& Berdahl, J. L. (2002). The experience of power: Examining the effects of power on approach and inhibition tendencies. Journal of Personality and Social Psychology, 83, 1362-1377. doi: 0.1037/0022-3514.83.6.1362

Appelbaum, S. H., Marchionni, A., \& Fernandez, A. (2008). The multi-tasking paradox: perceptions, problems and strategies. Management Decision, 46(9), 1313-1325. doi: $10.1108 / 00251740810911966$

Arrington, C. M., \& Logan, G. D. (2004). The cost of a voluntary task switch. Psychological Science, 15, 610-615. doi: 10.3389/fpsyg.2011.00031

Arrington, C. M., \& Logan, G. D. (2005). Voluntary task-switching: Chasing the elusive homunculus. Journal of Experimental Psychology: Learning, Memory, and Cognition, 31, 683-702. doi: 10.1037/0278-7393.31.4.683

Baddeley, A. (1992). Working Memory. Science, 255(5044), 556-559.

Baddeley, A. D. (1996). The concept of working memory. In S. Gathercole (Ed.), Models of short-term memory (pp. 1-28). Hove, UK: Lawrence Erlbaum Associates.

Bates, D. (2012, July 31). You've got (more) mail: The average office worker now spends over a quarter of their day dealing with email. Mail Online. Retrieved from http://www.dailymail.co.uk/ 
Bill, G. (2010, Mar 22). Today's leadership style: Empowering employees at all levels is replacing 'command and control' structure to achieve superior performance. The Wall Street Journal Asia, p. 31.

Bluedorn, A. C., Kalliath, T. J., Strube, M. J., \& Martin, G. D. (1999). Polychronicity and the Inventory of Polychronic Values (IPV): The development of an instrument to measure a fundamental dimension of organizational culture. Journal of Managerial Psychology, 14(3/4), 205-231. doi: 10.1108/02683949910263747

Borenstein, M., Hedges, L., Higgins, J., \& Rothstein, H. (2005). Comprehensive MetaAnalysis Version 2. Engelwood, NJ: Biostat.

Briñol, P., Petty, R. E., Valle, C., Rucker, D. D., \& Becerra, A. (2007). The effects of message recipients' power before and after persuasion: A self-validation analysis. Journal of Personality and Social Psychology, 93, 1040-1053. doi: 10.1037/00223514.93.6.1040

Brown, J. M., Miller, W. R., \& Lawendowski, L. A. (1999). The Self-Regulation Questionnaire. In L. VandeCreek \& Jackson (Eds.), Innovations in clinical practice: A source book (Vol. 17, pp. 281-289). Sarasota, FL: Professional Resource Press.

Buhner, M., Konig, C.J., Pick, M., \& Krumm, S. (2006). Working memory dimensions as differential predictors of the speed and error aspect of multitasking performance. Human Performance, 19, 253-275.

Cai, A., \& Guinote, A. Lack of Power Increases the Tendency to Multitask. Manuscript in preparation.

Carver, C. (2003). Pleasure as a sign you can attend to something else: Placing positive feelings within a general model of affect. Cognition \& Emotion, 17(2), 241-261. doi: 
10.1080/02699930302294 Chua, R. Y .J., \& Iyengar, S. (2006). Empowerment through Choice? A Critical Analysis of the Effects of Choice in Organizations. Research in Organizational Behavior, 27, 41-79. doi: 10.1016/S0191$3085(06) 27002-3$

Cohen, J. (1988). Statistical power analysis for the behvarioral sciences ( $2^{\text {nd }}$ ed). Hillsdale, NJ: Lawrence Earlbaum Associates.

Derakshan, N., \& Eysenck, M. W. (2009). Anxiety, processing efficiency, and cognitive performance. European Psychologist, 14(2), 168-176. doi: 10.1027/10169040.14 .2 .168

Derryberry, D., \& Reed, M. A. (2002). Anxiety-related attentional biases and their regulation by attentional control. Journal of Abnormal Psychology, 111(2), 225-236. doi: 10.1037/0021-843X.111.2.225

DeWall C. N., Baumeister, R. F., Mead, N. L., \& Vohs, K. D. (2011). How leaders selfregulate their task performance: Evidence that power promotes diligence, depletion, and disdain. Journal of Personality and Social Psychology, 100(1), 47-65. doi: $10.1037 / \mathrm{a} 0020932$

Elovainio, M., Singh-Manoux, A., Ferrie, J. E., Shipley, M., Gimeno, D., De Vogli, R., . . Kivimäki, M. (2012). Organisational justice and cognitive function in middle-aged employees: the Whitehall II study. Journal of Epidemiology and Community Health, 66 (6), 552-556. doi:10.1136/jech.2010.113407 
Fast, N. J., Sivanathan, N., Mayer, N. D., \& Galinsky, A. D. (2012). Power and overconfident decision-making. Organizational Behavior and Human Decision Processes, 117, 249260. doi: 10.1016/j.obhdp.2011.11.009

Faul, F., Erdfelder, E., Lang, A.-G. \& Buchner, A. (2007). G*Power 3: A flexible statistical power analysis program for the social, behavioral, and biomedical sciences. Behavior Research Methods, 39, 175-191.

Fernandez, S., \& Molgaziev, T. (2011). Empowering public sector employees to improve performance: Does it work? The American Review of Public Administration, 41(1), 23-47. doi:10.1177/0275074009355943

Fishbach, A. \& Ferguson, M. F. (2007). The Goal Construct in Social Psychology. In A. W. Kruglanski \& T. E. Higgins (Eds.), Social Psychology: Handbook of Basic Principles (pp. 490-515). New York, NY: Guilford.

Fiske, S. T. (1993). Social Cognition and Social Perception. Annual Review of Psychology, 44(1), 155-194. doi: 10.1146/annurev.ps.44.020193.001103

Fiske, S. T., \& Dépret, E. (1996). Control, Interdependence and Power: Understanding Social Cognition in Its Social Context. European Review of Social Psychology, 7(1), 31-61. doi:10.1080/14792779443000094

Foehr, U. (2006, December). Media multitasking among American youth: Prevalence, predictors and pairings. Kaiser Family Foundation. Retrieved from http://www.kff.org/entmedia/upload/7592.pdf

Friedman, N.P., Miyake, A., Corley, R.P., Young, S.E., DeFries, J.C., \& Hewitt, J.K. (2006). Not all executive functions are related to intelligence. Psychological Science, 17(2), 172-179. doi: 10.1111/j.1467-9280.2006.01681.x 
Galinsky, A. D., Gruenfeld, D. H., \& Magee, J. C. (2003). From Power to Action. Journal of Personality and Social Psychology, 85(3), 453-466. doi: 10.1037/0022-3514.85.3.453

González, V., \& G. Mark. (2005). Managing currents of work: Multi-tasking among multiple collaborations. In Proceedings of the $9^{\text {th }}$ European Conference of Computersupported Cooperative Work (ECSW) (pp. 143-162). The Netherlands: Springer.

Gray, J.A. (1982). The Neuropsychology of Anxiety. New York, NY: Oxford University Press.

Guinote, A. (2007a). Behaviour variability and the situated focus theory of power. European review of social psychology, 18(1), 256-295. doi: 10.1080/10463280701692813

Guinote, A. (2007b). Power affects basic cognition: Increased attentional inhibition and flexibility. Journal of Experimental Social Psychology, 43(5), 685-697. doi: 0.1016/j.jesp.2006.06.008

Guinote, A. (2007c). Power and Goal Pursuit. Personality and Social Psychology Bulletin, 33(8), 1076-1087. doi: 10.1177/0146167207301011

Guinote, A. (2008). Power and affordances: When the situation has more power over powerful than powerless individuals. Journal of Personality and Social Psychology, 95(2), 237. doi: 10.1037/a0012518

Guinote, A. (in press). How power affects people: Activation, wanting, and goal seeking. Annual Review of Psychology, 68.

Hambrick, D. Z., Oswald, F. L., Darowski, E. S., Rench, T. A., \& Brou, R. (2009). Predictors of Multitasking Performance in a Synthetic Work Paradigm. Applied Cognitive Psychology, 24, 1149-1167. 
Harada, T., Bridge, D. J., \& Chiao, J. Y. (2012). Dynamic social power modulates neural basis of math calculation. Frontiers in Human Neuroscience, 6, 350. doi:10.3389/fnhum.2012.00350

Hassan, S., Wright, B. E., Park, J. (2016). The role of employee task performance and learning effort in determining empowering managerial practices. Review of Public Personnel Administration, 36(1), 57-79.

Hester, R., \& Garavan, H. (2005). Working memory and executive function: The influence of content and load on the control of attention. Memory \& cognition, 33(2), 221-233. doi: 10.3758/BF03195311

Kane, M. J., Hambrick, D. Z., Tuholski, S. W., Wilhelm, O., Payne, T. W., \& Engle, R. W. (2004). The generality of working memory capacity: a latent-variable approach to verbal and visuospatial memory span and reasoning. Journal of Experimental Psychology: General, 133(2), 189.

Keltner, D., Gruenfeld, D. H., \& Anderson, C. (2003). Power, approach, and inhibition. Psychological review, 110(2), 265. doi:10.1037/0033-295X.110.2.265

Kiesel, A., Wendt, M., \& Peters, A. (2007). Task-switching: on the origin of response congruency effects. Psychological Research, 71, 117-125. doi: 10.1007/s00426-0050004-8

Kruglanski, A. W., Shah, J. Y., Fishbach, A., Friedman, R., Chun, W. Y., \& Sleeth-Keppler, D. (2002). A theory of goal systems. In M. P. Zanna (Ed.) Advances in experimental social psychology (Vol. 34, pp. 331-378). San Diego: Academic Press. 
Lammers, J., Dubois, D., Rucker, D. D., \& Galinsky, A. D. (2013). Power gets the job: Priming power improves interview outcomes. Journal of Experiment Social Psychology, 49(4), 776-779. doi:10.1016/j.jesp.2013.02.008

Lavie, N., Hirst, A., De Fockert, J.W., Viding, E. ( 2004). Load theory of selective attention and cognitive control. Journal of Experimental Psychology General, 133, 339-354. doi: 10.1037/0096-3445.133.3.339

Lehle, C., Steinhauser, M., \& Hubner, R. (2009). Serial or parallel processing in dual tasks: What is more effortful? Psychophysiology, 46, 502-509. doi: 10.1111/j.14698986.2009.00806.x

Levy, J., \& Pashler, H. (2001). Is dual-task slowing instruction dependent? Journal of Experimental Psychology: Human Perception and Performance, 27(4), 862. doi: $10.1037 / / 0096-1523.27 .4 .862$

Lindbeck, A., \& Snower, D. (2000). Multi-task learning and the reorganization of work. Journal of Labor Economics, 18(3), 353-376.

Lipsey, M. W., \& Wilson, D. B. (2001). Practical meta-analysis. Thousand Oaks, CA: Sage.

Magee, J. C., Galinsky, A. D., \& Gruenfeld, D. H. (2007). Power, propensity to negotiate, and moving first in competitive interactions. Personality and Social Psychology Bulletin, 33(2), 200-212.

Marmot, M. (2000). Health and socioeconomic status. In G. Find (Ed.), Encyclopedia of Stress (pp. 313-322). Sand Diego: Academic Press. 
Marteau, T. M., \& Bekker, H. (1992). The development of a six-item short-form of the state scale of the Spielberger State-Trait Anxiety Inventory (STAI). British Journal of Clinical Psychology, 31(3), 301-306.

Mayr, U., \& Keele, S. (2000). Changing internal constraints on action: The role of backward inhibition. Journal of Experimental Psychology: General, 129, 4-26. doi: 10.3410/f.1002662.29763

Meyer, D. E., \& Kieras D. E. (1997). A computational theory of executive cognitive processes and multiple-task performance: part I, basic mechanisms. Psychological Review, 104(1), 3-65.

Miyake, A., Friedman, N. P., Emerson, M. J., Witzki, A. H., Howerter, A, \& Wager, T. D. (2000). The unity and diversity of executive functions and their contributions to complex "Frontal Lobe" tasks: a latent variable analysis. Cognitive Psychology, 41(1), 49-100. doi:10.1006/cogp.1999.0734

Mitchell, J. P., Macrae, C. N., \& Gilchrist, I. D. (2002). Working memory and the suppression of reflexive saccades. Journal of Cognitive Neuroscience, 14(1), 95-103. doi: $10.1162 / 089892902317205357$

Monsell, S. (2003). Task-switching. Trends in Cognitive Sciences, 7(3), 134-140. doi:10.1016/S1364-6613(03)00028-7

Ophir, E., Nass, C., \& Wagner, A. D. (2009). Cognitive control in media multitaskers. Proceedings of the National Academy of Sciences, 106 (37), 15583-15587. doi: 10.1073/pnas.0903620106 
Oswald, F. L., Hambrick, D. Z., \& Jones, L. A. (2007). Keeping all the plates spinning: Understanding and predicting multitasking performance. In D. H. Jonassen (Ed.), Learning to solve complex scientific problems. Mahwah, NJ: Erlbaum.

Overbeck, J. R., \& Park, B. (2006). Powerful perceivers, powerless objects: Flexibility of power holders' social attention. Organizational Behavior and Human Decision Processes, 99, 227-243. doi: 10.1016/j.obhdp.2005.10.003

Rogers, R. D., \& Monsell, S. (1995). Costs of a predictable switch between simple cognitive tasks. Journal of Experimental Psychology: General, 124, 207-231. doi: 0.1037/0894-4105.20.6.675

Rokke, P. Arnell, K., Koch, M. \& Andrews, J. (2002). Dual-task attention deficits in dysphoric mood. Journal of Abnormal Psychology, 111(2), 370-379. doi: 10.1037//0021-843X.111.2.370

Rubinstein, J. S., Meyer, D. E., \& Evans, J. E. (2001). Executive control of cognitive processes in task-switching. Journal of Experimental Psychology. Human Perception and Performance, 27(4), 763-797. doi: 10.1037/0096-1523.27.4.763

Scheepers, D., De Wit, F., Ellemers, N., \& Sassenberg, K. (2012). Social power makes the heart work more efficiently: Evidence from cardiovascular markers of challenge and threat. Journal of Experimental Social Psychology, 48, 371-374. doi: 10.1016/j.jesp.2011.06.014

Schmid, P. C., Kleiman, T., \& Amodio, D. M. (2015). Power effects on cognitive control: turning conflict into action. Journal of Experimental Psychology General, 144(3), 655663. doi: $10.1037 / x$ ge0000068 
Schmid, P. C., Schmid Mast, M., \& Mast, F. W. (2015). Prioritizing-The task strategy of the powerful? The Quarterly Journal of Experimental Psychology, 68(10), 2097-2105.

Schubert, T. (2008). The central attentional limitation and executive control. Frontiers of Bioscience, 13, 3569-3580. doi:10.2741/2950

Schumacher, E. H., Seymour, T. L., Glass, J. M., Fencsik, D. E., Lauber, E. J., Kieras, D. E., \& Meyer, D. E. (2001). Virtually perfect time sharing in dual-task performance: uncorking the central cognitive bottleneck. Psychological Science, 12(2), 101-8. doi:10.1111/1467-9280.00318

Seibert, P.S., \& Ellis, H.C. (1991). Irrelevant thoughts, emotional mood states, and cognitive task performance. Memory and Cognition, 1, 507-513. doi: 10.3758/BF03199574

Seibert, S. E., Wang, G., \& Courtright, S. H. (2011). Antecedents and consequences of psychological and team empowerment in organizations: a meta-analytic review. Journal of Applied Psychology, 96(5), 981.

Shah, J.Y. (2005). The automatic pursuit and management of goals. Current Directions in Psychological Science, 14, 10-13.

Slabu, L., \& Guinote, A. (2010). Getting what you want: Power increases the accessibility of active goals. Journal of Experimental Social Psychology, 46(2), 344-349. doi: 10.1016/j.jesp.2009.10.013

Smith, P. K., Jostmann, N. B., Galinsky, A. D., \& van Dijk, W. W. (2008). Lacking Power Impairs Executive Functions. Psychological Science, 19(5), 441-447. doi: 10.1111/j.1467-9280.2008.02107.x 
Szameitat, A. J., Schubert, T., Müller, K., \& von Cramon, D. Y. (2002). Localization of executive functions in dual-task performance with fMRI. Journal of Cognitive Neuroscience, 14(8), 1184-1199. doi: 10.1162/089892902760807195

Wallace, J. C., Johnson, P. D., Mathe, K., \& Paul, J. (2011). Structural and psychological empowerment climates, performance, and the moderating role of shared felt accountability: a managerial perspective. Journal of Applied Psychology, 96(4), 840850. doi:10.1037/a0022227

\section{Footnotes}

${ }^{1} \mathrm{~A}$ Bonferroni correction was used because the result was unexpected. 
Table 1

Means and SDs for Single and Dual-task RTs and ERs as a Function of Power (Study 2)

\begin{tabular}{|c|c|c|c|c|c|c|c|c|}
\hline \multirow{3}{*}{ Power } & \multicolumn{4}{|c|}{ RT (ms) } & \multicolumn{4}{|c|}{ ERs (\%) } \\
\hline & \multicolumn{2}{|c|}{ Single-Task } & \multicolumn{2}{|c|}{ Dual-Task } & \multicolumn{2}{|c|}{ Single-Task } & \multicolumn{2}{|c|}{ Dual-Task } \\
\hline & $\mathrm{M}$ & SD & $\mathrm{M}$ & $\mathrm{SD}$ & $\mathrm{M}$ & SD & $\mathrm{M}$ & SD \\
\hline Powerless & 492 & 64.5 & 764 & 215 & 3.40 & 2.94 & 4.72 & 2.79 \\
\hline Control & 528 & 73.8 & 685 & 168 & 2.66 & 2.37 & 3.45 & 2.94 \\
\hline Powerful & 531 & 88.5 & 687 & 102 & 2.01 & 1.65 & 3.18 & 2.03 \\
\hline
\end{tabular}

Note. Higher values indicate worse performance (slower RTs and higher ERs). 
Table 2

Means and SDs for Repeat and Switch trials RTs and ERs as a Function of Power (Study 3)

\begin{tabular}{lcccccccc}
\hline & \multicolumn{3}{c}{ RT (ms) } & \multicolumn{5}{c}{ ER (\%) } \\
\cline { 2 - 9 } Power & \multicolumn{1}{c}{ Repeat Trials } & Switch Trials & \multicolumn{2}{c}{ Repeat Trials } & \multicolumn{2}{c}{ Switch Trials } \\
\cline { 2 - 9 } & M & SD & M & SD & M & SD & M & SD \\
\hline Powerless & 1280 & 400 & 1468 & 468 & 0.86 & 1.04 & 2.11 & 1.91 \\
Control & 1050 & 195 & 1300 & 309 & 1.08 & 1.16 & 0.90 & 0.99 \\
Powerful & 1084 & 269 & 1280 & 318 & 1.01 & 1.09 & 1.31 & 1.39 \\
\hline
\end{tabular}

Note. Higher values indicate higher RTs and ERs. 


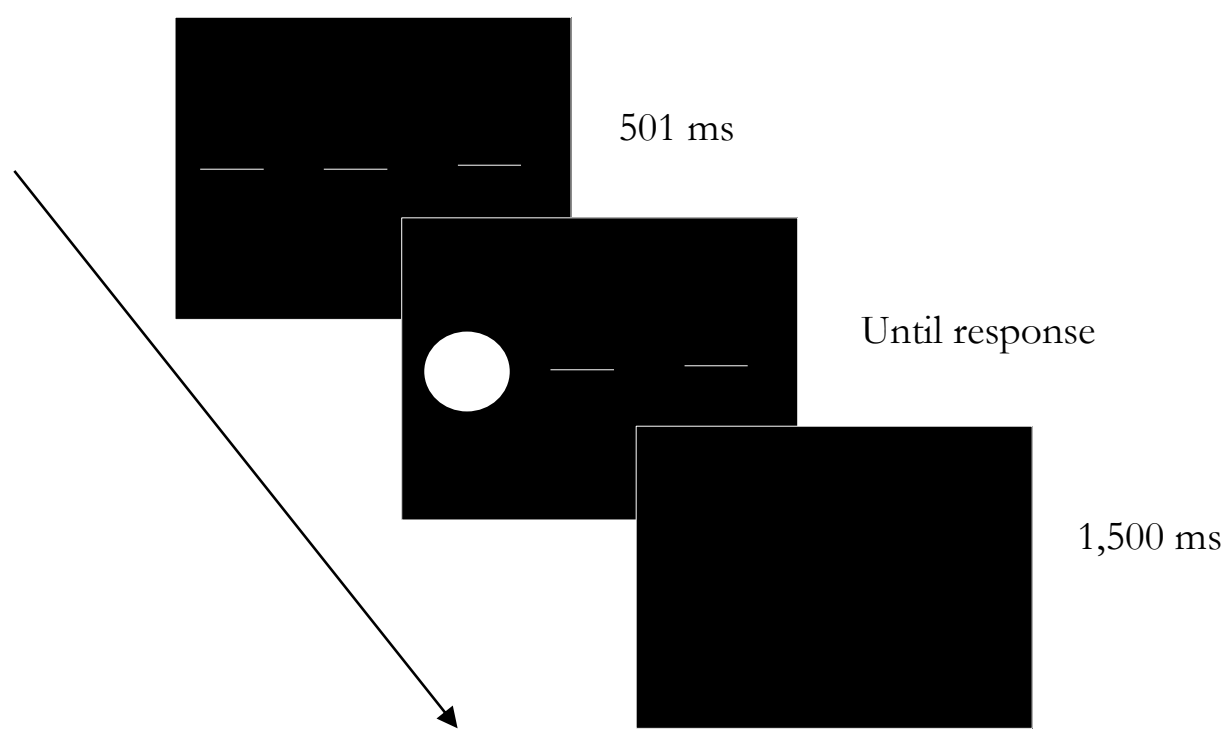

Figure 1. Example of a sequence of events in a trial of Study 2. 


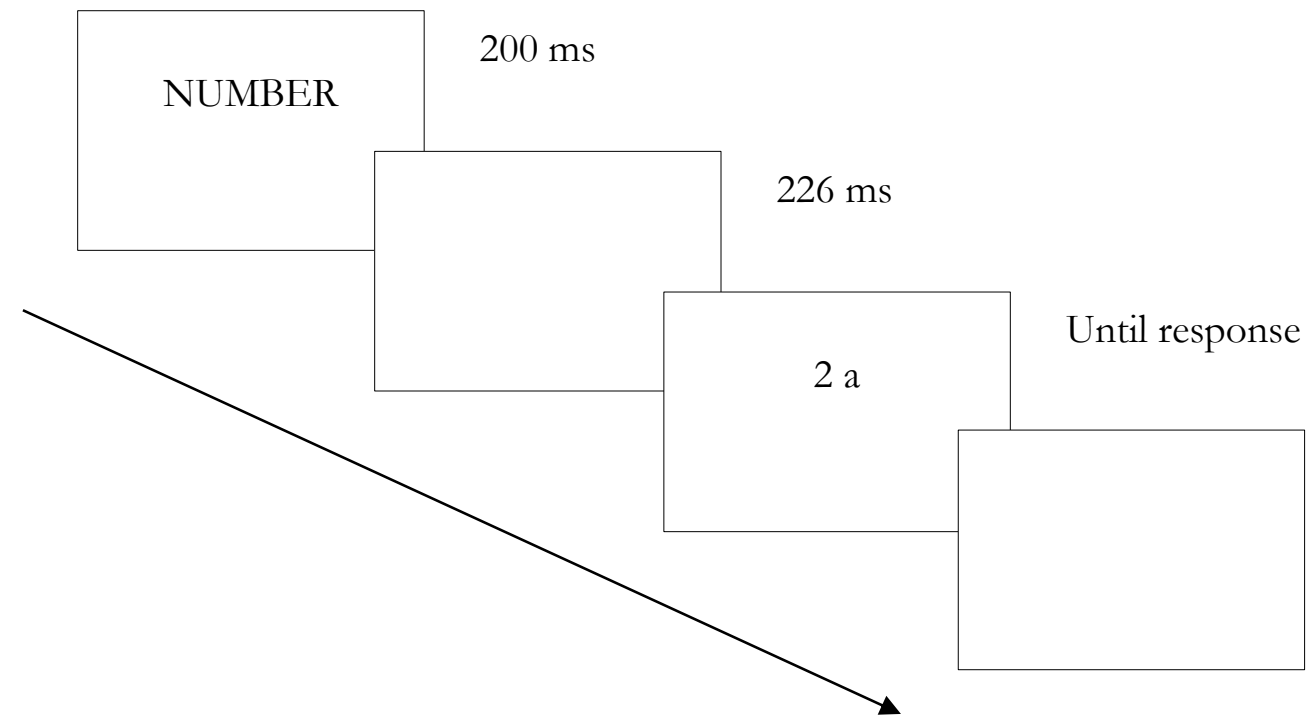

$950 \mathrm{~ms}$

Figure 2. Example of a sequence of events in a trial of Study 3. 